\title{
Secondary Metabolite Profiling in Various Parts of Tomato Plants
}

\author{
Dong Sub Kim ${ }^{1 \dagger}$, Haeyoung $\mathrm{Na}^{2 \dagger}$, Yurina Kwack ${ }^{3}$, and Changhoo Chun ${ }^{1,3^{*}}$ \\ ${ }^{1}$ Department of Plant Science, Seoul National University, Seoul 151-921, Korea \\ ${ }^{2}$ Department of Horticultural Science, Mokpo National University, Muan 534-729, Korea \\ ${ }^{3}$ Research Institute for Agriculture and Life Sciences, Seoul National University, Seoul 151-921, Korea
}

\begin{abstract}
Contents of carotenoids, phenolic compounds, volatile organic compounds, and alkaloids in leaves, internodes, fruits, and roots of tomatoes in different developmental stages were measured. Lycopene, $\beta$-carotene, and lutein were detected in all the tested parts except roots and green fruits. Lycopene content in red fruits was $49.04 \mu \mathrm{g} \cdot \mathrm{g}^{-1} \mathrm{FW}$, while that in the other parts was below $40 \mu \mathrm{g} \cdot \mathrm{g}^{-1} \mathrm{FW}$. $\beta$-Carotene and lutein contents in 24 th leaves were 5.81 and $6.40 \mu \mathrm{g} \cdot \mathrm{g}^{-1} \mathrm{FW}$, respectively, and were greater than those in the other parts. Caffeic, chlorogenic, and vanillic acids were detected in all the tested parts except roots. The content of chlorogenic acid in the 18 th leaves was $40.11 \mu \mathrm{g} \cdot \mathrm{g}^{-1} \mathrm{FW}$, while that in the other parts was lower than $31.00 \mu \mathrm{g} \cdot \mathrm{g}^{-1} \mathrm{FW}$. The contents of caffeic and vanillic acids in the 24th leaves were 9.18 and $1.64 \mu \mathrm{g} \cdot \mathrm{g}^{-1} \mathrm{FW}$, respectively, and were greater than those in the other parts. Moreover, younger leaves contained the more diverse volatile organic compounds including monoterpenes and sesquiterpenes. Contents of dehydro-tomatine and $\alpha$-tomatine were greatest in leaves, followed by internodes, roots and fruits. Younger leaves and internodes contained more dehydro-tomatine and $\alpha$-tomatine than older leaves and internodes. The contents of dehydro-tomatine and $\alpha$-tomatine in the 24 th leaves were 0.89 and $1.42 \mathrm{mg} \cdot \mathrm{g}^{-1} \mathrm{FW}$, respectively, and were greatest among all the tested parts. Our results indicated that, except lycopene, tomato leaves included greater secondary metabolites contents than red fruits. The results suggest that inedible parts of tomato plants can be used as raw material for antioxidants, anti-inflammatory agents, fungistats, and pesticides.
\end{abstract}

Additional key words: alkaloids, carotenoids, phenolic compounds, volatile organic compounds

\section{Introduction}

Secondary metabolites are diverse compounds found in terrestrial and marine plant species. Plants produce secondary metabolites under biotic or abiotic stress because the compounds have antimicrobial, anti-herbivory, and allopathic effects (Dixon, 2001). In addition, various secondary metabolites show other beneficial properties such as color, scent, and flavor attractants (Frydman et al., 2004; Rohloff and Bones, 2005; Verdonk et al., 2003), UV-protectants, antioxidants, signaling factors, and nutraceutical and pharmacological efficacies (Aerts et al., 1999; Bagchi et al., 2000; Deavours and Dixon, 2005; D'Haeze and Holsters, 2002; Gidley, 2004; Manach et al., 2004; Merz-Demlow et al., 2000; Oldroyd,
2001; Relić et al., 1994; Setchell and Cassidy, 1999).

Tomato (Solanum lycopersicum L.) is known as a plant that contains many secondary metabolites. Profiling of secondary metabolites in tomato plants, particularly the fruits, has been performed by analysis of carotenoids (Moco et al., 2007), phenolic compounds (Slimestad and Verheul, 2009), volatile organic compounds (Buttery et al., 1987), and alkaloids (Friedman and Levin, 1998).

The carotenoids are important color compounds in flowers, food, and fruits (Verpoorte and Memelink, 2002). Lycopene is the most abundant secondary metabolites in fully red ripe tomato fruits. This carotenoids a natural pigment synthesized by plants to protect cells against oxidative damage (Rao and Agarwal, 1999) and to attract pollinators (Moco et al.,

\footnotetext{
*Comesponding author: changhoo@snu.ac.kr

${ }^{\dagger}$ These authorsare contributed equally to this work.

※ Received 22 October 2013; Revised 19 November 2013; Accepted 27 November 2013. This study was supported by "Regional Joint Agricultural Research Project of RDA (granted No. 20110801030507)” granted by RDA, Korea.

(C) 2014 Korean Society for Horticultural Science
} 
2007). Moreover, researchers have reported that lycopene induces communication between cells (Zhang et al., 1991) and controls immune systems and other metabolic pathways (Astorg et al., 1997; Fuhrman et al., 1997). Tomatoes also include $\beta$-carotene and lutein. $\beta$-Carotene is known for its provitamin A activity and lutein for its anticancer activity against lung cancer (Di Mascio et al., 1991).

Phenolic compounds are known to possess antimicrobial and antiviral properties (Dixon, 2001; French and Neil Towers, 1992). Many phenolic compounds in tomato fruits have also been found (Slimestad and Verheul, 2009). Walker (1962) reported that caffeic, chlorogenic, $p$-coumaric, and ferulic acids are found in tomato fruits, and contents of caffeic and chlorogenic acids decrease through the fruit development process. Wardale (1973) reported that chlorogenic acid is the major phenolic compound contained in fruits of various tomato cultivars, accounting for $75 \%$ of the total phenolics in mature green fruit and 35\% in ripe fruit.

Volatile organic compounds in tomato plants affect the behaviors of pests and pollinators of tomato (Buttery et al., 1987). Andersson et al. (1980) who identified monoand sesquiterpenes in tomato leaves had previously reported the volatile compounds of tomato. Urbasch (1981) additionally identified hexanal, $(E)$-2-hexenal, (Z)-and (E)- $\beta$-ocimeneterpinolene, linalool, neral, geranial, methyl salicylate, nerol, geraniol, and 2-tridecanone. Buttery et al. (1987) improved upon the detection and isolation of mono- and sesquiterpenes and aliphatic and aromatic compounds in tomato leaves.

Tomatine from tomato was firstly isolated by Fontaine et al. in 1948. Friedman and Levin (1998) identified dehydroand $\alpha$-tomatine in various parts of tomato plant. These tomato glycoalkaloids are of interest because of their implication in host-plant resistance. In particular, $\alpha$-tomatineis expected to protect tomato leaves against attack by microorganisms (Morrissey and Osbourn, 1999). Sandrock and Van Etten (1998) reported that growth of eight saprophytic fungi and the tomato pathogens Stemphylium solani 11128 and Verticillium dahlia were greatly inhibited by $\alpha$-tomatine.

Some studies indicated that in edible parts of vegetables are available because they contain higher contents of secondary metabolites than edible parts. For instance, the leaves of strawberry and carrot include higher contents of phenolic compounds than edible parts (Kähkönenet al., 1999; Kim et al., 2013). The previous researches, however, have analyzed the contents of secondary metabolites in ripe fruits of tomato plants but few studies have reported the metabolites in inedible parts such as leaves, internodes, unripe fruits, and roots. The objective of this study was to identify the carotenoids, phenolic compounds, volatile organic compounds, and alkaloids present in leaves, internodes, fruits, and roots of tomato plants.

\section{Materials and Methods}

\section{Plant Materials}

'Bacchus' tomato plants (Monsanto Korea, Chochiwon, Korea) were transplanted in a greenhouse located in Gwangiu (N 35.26, E 126.74; Korea) on August 19, 2011. The plants were fertigated with Yamasaki nutrition solution $(\mathrm{N} ; 7.0$ $\mathrm{me} \cdot \mathrm{L}^{-1}, \mathrm{P} ; 2.0 \mathrm{me} \cdot \mathrm{L}^{-1}, \mathrm{~K} ; 4.0 \mathrm{me} \cdot \mathrm{L}^{-1}$, Ca; $3.0 \mathrm{me} \cdot \mathrm{L}^{-1}, \mathrm{Mg}$; $2.0 \mathrm{me} \cdot \mathrm{L}^{-1}, \mathrm{Fe} ; 15.38 \mathrm{mg} \cdot \mathrm{L}^{-1}, \mathrm{~B} ; 1.14 \mathrm{mg} \cdot \mathrm{L}^{-1}, \mathrm{Mn} ; 0.81 \cdot \mathrm{mg} \mathrm{L}^{-1}$, $\mathrm{Zn} ; 0.09 \mathrm{mg} \cdot \mathrm{L}^{-1}, \mathrm{Cu}$; $\left.0.04 \mathrm{mg} \cdot \mathrm{L}^{-1}, \mathrm{Mo} ; 0.01 \mathrm{mg} \cdot \mathrm{L}^{-1}\right)$ using an automatic drip fertigation system $(\mathrm{pH} ; 5.5-6.0, \mathrm{EC}$; 2.0-2.5 dS $\cdot \mathrm{m}^{-1}$ ) and were pinched off at the two leaves above the 6th flower truss. Roots, 18th (above the 4th flower truss), 21th (above the 5th flower truss), and 24th (above the 6th flower truss) leaves and internodes, and green, pink, and red fruits were harvested on May 15, 2012.

Fruits were classified into three ripening stages by the percentage of red color: $0 \%$ (green); more than 30\% but not more than $60 \%$ (pink); more than $90 \%$ (red). After classification, samples were stored at $-20^{\circ} \mathrm{C}$ until phytochemical analysis.

\section{Analysis of Carotenoids}

The hexane extraction method was performed as in Sadler et al. (1990). Samples (4 g) were weighed into $125 \mathrm{~mL}$ flasks and the flasks were sealed with aluminum foil to block light. A hexane:acetone:ethanol (50:25:25) solvent $(100 \mathrm{~mL})$ was added to the flask and then agitated for $10 \mathrm{~min}$. Finally, water $(15 \mathrm{~mL})$ was added, followed by another $5 \mathrm{~min}$ agitation. The solution separated into distinct polar $(65 \mathrm{~mL})$ and nonpolar $(50 \mathrm{~mL})$ layers. The carotenoids in the upper hexane layer were measured using a spectrophotometer (UV-2550, Shimadzu, Kyoto, Japan). The lycopene, $\beta$-carotene, and lutein contents of each sample were then estimated using absorbance at 503, 455, and $446 \mathrm{~nm}$, respectively.

\section{Analysis of Phenolic Compounds}

Phenolic compounds were extracted and hydrolyzed according to the process described in Nuutila et al. (2002). Different parts $(5 \mathrm{~g})$ of the tomato plant were homogenized with $5 \mathrm{~mL}$ of $1.2 \mathrm{M} \mathrm{HCl}$ in $50 \%(\mathrm{v} / \mathrm{v})$ aqueous methanol. Ascorbic acid (8 $\mathrm{mg}$ ) was added to the mixture as an antioxidant. After agitating at $35^{\circ} \mathrm{C}$ for $16 \mathrm{~h}$, the extract 
was cooled, made up to $10 \mathrm{~mL}$, and sonicated for $3 \mathrm{~min}$. The extract was filtered through a $0.45 \mu \mathrm{m}$ syringe filter before injection to the HPLC apparatus (Ultimate 3000, Dionex, Sunnyvale, CA, USA). The mobile phase involved a $20-60 \%$ gradient of methanol in water with $300 \mathrm{~mL} \cdot \mathrm{L}^{-1}$ trifluoroacetic acid, eluted at a flow rate of $0.8 \mathrm{~mL} \cdot \mathrm{min}^{-1}$ for $25 \mathrm{~min}$. After each analysis, the column was washed with $100 \%$ methanol for $2 \mathrm{~min}$, returned to $20 \%$ methanol, and re-equilibrated for $10 \mathrm{~min}$ before the next analysis. The eluted components were monitored using a UV/Vis detector at 280 and $340 \mathrm{~nm}$ with a Zorbax SB C-18 column, $150 \times 4.6$ mm, i.d. 5 mm (Agilent Co., New York, NY, USA). Analytical standards were trans-cinnamic acid, $p$-coumaric acid, caffeic acid, chlorogenic acid, gallic acid, ellagic acid, p-hydrobenzoic acid, 2,5-hydrobenzoic acid, 3,4-hydrobenzoic acid, vanillic acid, kaempferol, quercetin, and morin.

\section{Analysis of Volatile Organic Compounds}

Volatile organic compounds were determined using the procedure described by Isleten and Karagül-Yüceer (2008). The sample gas was gathered by Tenax-TA (PerkinElmer Life and Analytical Sciences Inc., Waltham, MA, USA), a dynamic thermal extractor chamber system, which consists of a $26 \mathrm{~mL}$ glass tube and an air control system, containing an air supply unit and pumps. Purified nitrogen gas (39 $\mathrm{mL} \cdot \mathrm{min}^{-1}$ ) was consumed for ventilation. Volatile organic compounds in different parts of tomato plant were analyzed by thermal desorption gas chromatograph mass spectrometry (TDS-GC MSD and TDS2, Gerstel GmbH \& Co. KG, Mülheim, Germany; 6890N and 5975, Agilent Technologies, Inc. Santa Clara, CA, USA).

\section{Analysis of Tomatines}

Tomatines were isolated and identified by the method of Friedman and Levin (1998). Samples (1 g in $20 \mathrm{~mL}$ of $1 \%$ acetic acid) were extracted by stirring for $2 \mathrm{~h}$. The suspension was centrifuged at 13,300 RCF for $10 \mathrm{~min}$. The supernatant was filtered through a Whatman GF/C filter and the pellet was resuspended, centrifuged, and filtered. The two extracts were combined. The extract was purified using SPE. C18 SPE tubes were conditioned with methanol $(5 \mathrm{~mL})$ followed by water $(5 \mathrm{~mL})$. The extract (about $30 \mathrm{~mL}$ ) was allowed to gravity drip. When the sample was fully absorbed, the tube was washed with about water (10 mL), followed by $5 \mathrm{~mL}$ of $30: 70$ acetonitrile/1\% $\mathrm{NH}_{4} \mathrm{OH}$, and then water (5 mL). The dehydrotomatine and $\alpha$-tomatine were eluted with $10 \mathrm{~mL}$ of $70: 30$ acetonitrile/1 $\mathrm{mM} \mathrm{HCl}$. The sample was dried on a rotovapor and the residue was taken up in $1 \mathrm{~mL}$ of $50 \%$ methanol/0.1\% acetic acid. The two samples were combined and filtered through a $0.45 \mu \mathrm{m}$ HV membrane before HPLC injection.

Commercial tomatine (Tokyo chemical industry Co., Tokyo, Japan) was separated into dehydrotomatine and $\alpha$-tomatine by preparative HPLC using UV detection. Conditions were asfollows: $3 \mathrm{~mL}$ of eluent/min was passed through a 150 $\times 4.6 \mathrm{~mm}$, i.d. $5 \mu \mathrm{m}$, Zorbax SB C-18 column; the eluent consisted of $25 \%$ acetonitrile and $100 \mathrm{mM}$ ammonium phosphate brought to $\mathrm{pH} 3$ with phosphoric acid. Tomatine ( $2 \mathrm{mg}$ in $1 \mathrm{~mL}$ of $50 \%$ methanol and $0.1 \%$ acetic acid) was injected to the column; the two peaks were collected from the UV detector, which was observed at $200 \mathrm{~nm}$. The structures of the dehydrotomatine and $\alpha$-tomatine were confirmed by mass spectrometry. The HPLC eluent for tomatine analysis was prepared by combining buffer $(100 \mathrm{~mL})$ with polished water $(550 \mathrm{~mL})$, acetonitrile (200 $\mathrm{mL})$, and methanol (150 $\mathrm{mL})$. The concentrated buffer was prepared by combining disodium phosphate (28.97 g) and citric acid (93.72 g) in water (1 L). This buffer was filtered through a $0.45 \mu \mathrm{m}$ nylon membrane, passed through a $3 \times 1 \mathrm{~cm}$ bed of Chelex 100, and then passed through a C18 SPE. The chromatography column was a $150 \times 4.6$ $\mathrm{mm}$, i.d. $5 \mu \mathrm{m}$, Zorbax SB C-18. Flow rate was set to 3 $\mathrm{mL} \cdot \mathrm{min}^{-1}$. Wavelength was monitored at $200 \mathrm{~nm}$.

\section{Statistical Analysis}

Statistical analyses were performed using SAS statistical software version 9.2 (SAS Institute Inc., Cary, NC, USA). Duncan's multiple range test was used to assess differences in contents of carotenoids, phenolic compounds, and alkaloids. $P \leq 0.05$ was considered statistically significant.

\section{Results and Discussion}

\section{The Contents of Carotenoids}

Lycopene was only detected in the red fruits, with a content of $196.15 \mu \mathrm{g} \cdot \mathrm{g}^{-1} \mathrm{FW}$ (Table 1). Kozukue and Friedman (2003) and Lenucci et al. (2006) reported that lycopene content ranged from $58 \mathrm{mg} \cdot \mathrm{kg}^{-1}$ of fresh weight in 'Momotaro' cultivar to $253 \mathrm{mg} \cdot \mathrm{kg}^{-1}$ of fresh weigh in 'Kalvert' cultivar. Accumulation of lycopene generally begins at the 'breaker' stage after tomato fruit has reached the 'mature green stage'. Lycopene is mainly included in red-ripe tomato fruits (Approximately 80 to $90 \%$ of total pigment) (Lenucciet al., 2006). Ronen et al. (1999) reported that mRNA of CrtL-b which encodes lycopene $\beta$-cyclase and CrtL-e which encodes lycopene $\varepsilon$-cyclase decrease at the 'breaker' stage. 
Table 1. The contents of carotenoids in different parts of 'Bacchus' tomato plants.

\begin{tabular}{lcccc}
\hline \multirow{2}{*}{ Part } & & \multicolumn{3}{c}{ Carotenoids $\left(\mu \mathrm{g} \cdot \mathrm{g}^{-1} \mathrm{FW}\right)$} \\
\cline { 3 - 5 } & & Lycopene & $\beta$-carotene & Lutein \\
\hline Leaf & 18 th & n.d. $^{\mathrm{z}}$ & $14.60 \mathrm{c}$ & $17.91 \mathrm{~b}$ \\
& 21 th & n.d. & $20.13 \mathrm{~b}$ & $23.91 \mathrm{a}$ \\
& 24 th & n.d. & $23.23 \mathrm{a}$ & $25.61 \mathrm{a}$ \\
Internode & 18 th & n.d. & $1.19 \mathrm{~d}$ & $1.47 \mathrm{~d}$ \\
& 21th & n.d. & $1.54 \mathrm{~d}$ & $1.91 \mathrm{~d}$ \\
& 24th & n.d. & $1.50 \mathrm{~d}$ & $1.80 \mathrm{~d}$ \\
Fruit & Green & n.d. & n.d. & n.d. \\
& Pink & n.d. & n.d. & $1.06 \mathrm{~d}$ \\
& Red & $196.15 \mathrm{a}^{\mathrm{y}}$ & $3.37 \mathrm{~d}$ & $5.03 \mathrm{c}$ \\
Root & & n.d. & n.d. & n.d. \\
\hline
\end{tabular}

${ }^{\mathrm{z}}$ n.d.: non-detected.

${ }^{\mathrm{y}}$ Mean separation within columns by Duncan's multiple range test at $P<0.05$.

The content of $\beta$-carotene was 23.23, 20.13, 14.60, 3.37, $1.54,1.50$, and $1.19 \mu \mathrm{g} \cdot \mathrm{g}^{-1} \mathrm{FW}$ in 24th leaves, 21th leaves, 18th leaves, red fruits, 21th internodes, 24th internodes, and 18 th internodes, respectively (Table 1 ). $\beta$-carotene content in 24th leaves was 6.89 times greater than that in red fruits. The content of lutein was 25.61, 23.91, 17.91, 5.03, $1.91,1.80,1.47$, and $1.06 \mu \mathrm{g} \cdot \mathrm{g}^{-1} \mathrm{FW}$ in 24 th leaves, 21 th leaves, 18th leaves, red fruits, 21th internodes, 24th internodes, 18th internodes, and pink fruits, respectively (Table 1). Lutein content in 24th leaves was 5.09 times greater than that in red fruits. Fraser et al. (1994) also showed that tomato leaf contains $\beta$-carotene and lutein but not lycopene. Lycopene plays an attractant role in seed dispersal that can affect the further propagation (Moco et al., 2007) and $\beta$-carotene and lutein, major carotenoids in green leafy vegetables, are potent antioxidants (Jiménez-Escrig et al., 2000). The results show that leaves and red fruits of tomato contain more antioxidants and attractants, respectively.

\section{The Contents of Phenolic Compounds}

Caffeic, chlorogenic, and vanillic acids were detected in all tested parts except root (Table 2), while trans-cinnamic acid, $p$-coumaric acid, gallic acid, ellagic acid, $p$-hydrobenzoic acid, 2,5-hydrobenzoic acid, 3,4-hydrobenzoic acid, kaempferol, quercetin, and morin were not founded. Chen et al. (2006) and Slimestad and Verheul (2009) reported that chlorogenic acid and its derivatives are the main simple phenolics in tomato leaves and fruits. Slimestad and Verheul (2009)
Table 2. The contents of phenolic compounds in different parts of 'Bacchus' tomato plants.

\begin{tabular}{lcccc}
\hline \multirow{2}{*}{ Part } & & \multicolumn{2}{c}{ Phenolic compounds $\left(\mu \mathrm{g} \cdot \mathrm{g}^{-1} \mathrm{FW}\right)$} \\
\cline { 3 - 5 } & & $\begin{array}{c}\text { Chlorogenic } \\
\text { acid }\end{array}$ & $\begin{array}{c}\text { Caffeic } \\
\text { acid }\end{array}$ & $\begin{array}{c}\text { Vanillic } \\
\text { acid }\end{array}$ \\
\hline Leaf & 18th & $40.11 \mathrm{a}^{\mathrm{z}}$ & $6.14 \mathrm{~b}$ & n.d. \\
& 21th & $30.34 \mathrm{ab}$ & $5.07 \mathrm{~b}$ & $0.46 \mathrm{c}$ \\
& 24th & $25.97 \mathrm{ab}$ & $9.18 \mathrm{a}$ & $1.64 \mathrm{a}$ \\
Internode & 18th & $9.95 \mathrm{c}$ & $0.45 \mathrm{c}$ & $0.91 \mathrm{~b}$ \\
& 21th & $8.69 \mathrm{c}$ & $0.36 \mathrm{c}$ & $0.87 \mathrm{~b}$ \\
Fruit & 24th & $15.63 \mathrm{bc}$ & $0.28 \mathrm{c}$ & $0.81 \mathrm{~b}$ \\
& Green & $9.72 \mathrm{c}$ & $9.03 \mathrm{a}$ & $0.13 \mathrm{~d}$ \\
& Pink & n.d. & $3.84 \mathrm{~b}$ & n.d. \\
& Red & $7.69 \mathrm{c}$ & $6.53 \mathrm{ab}$ & $0.24 \mathrm{~d}$ \\
& & n.d. & n.d. & n.d.
\end{tabular}

${ }^{\mathrm{z}}$ Mean separation within columns by Duncan's multiple range test at $P<0.05$.

${ }^{\mathrm{y}}$ n.d.: non-detected.

reviewed that chlorogenic acid content ranged from 1.7 $\mathrm{mg} \cdot \mathrm{kg}^{-1}$ of fresh weight in 'Izabella' cultivar to $32.8 \mathrm{mg} \cdot \mathrm{kg}^{-1}$ of fresh weigh in 'Liso' and 'Senior' cultivars. Results from the present study also show that the content of chlorogenic acid was higher than that of caffeic and vanillic acids. The content of chlorogenic acid was 40.11, 30.34, 25.91, 15.63, 9.95, 9.72, 8.69, and $7.69 \mu \mathrm{g} \cdot \mathrm{g}^{-1} \mathrm{FW}$ in 18th leaves, 21th leaves, 24th leaves, 24th internodes, 18th internodes, green fruits, 21th internodes, and red fruits, respectively (Table 2). Chlorogenic acid content in 18th leaves was 5.22 times greater than that in red fruits. The difference of the contents of the chlorogenic acid in leaves and internodes may be due to their senescence late. Chlorogenic acid that presents in tomato leaves related to insect resistance decreases growth and development of several tomato herbivores (Elliger et al., 1981; Stamp and Yang, 1996). Moreover, the compound is produced in response to green bug (Todd et al., 1971) and black rot infection in resistant sweet potato roots (Akazawa and Wada, 1961; Uritaniand Akazawa, 1955). Chlorogenic acid also has numerous beneficial properties related to potent antioxidant activities such as hepatoprotective, hypoglycemic, and antiviral activities (Farah and Donangelo, 2006). Chlorogenic and caffeic acids are oxidized to more toxic quinones by polyphenol oxidase from the host or parasite, which then are polymerized to insoluble non-toxic melanins. Orthoquinones are very unstable, but the supplement of amino acids to the reactive 
center after orthophenol oxidation might prevent polymerization and could explain how the quinones provide disease resistance (Clack et al., 1959; Johnson and Schaal, 1957). The contents of caffeic and vanillic acids in 24th leaves were 9.18 and $1.64 \mu \mathrm{g} \cdot \mathrm{g}^{-1} \mathrm{FW}$, respectively, and was greater than that of the older leaves and other parts (Table 2). Brown et al. (2003) reported that young leaves of Arabidopsis have various secondary metabolites compared to old leaves, probably due to the re-allocation of secondary metabolites to decrease feeding by herbivores. Young leaves of strawberry plants also included greater content of phenolic compounds than old leaves (Kim et al., 2013). Antimicrobial activity of caffeic acid has been tested against various fungi and bacteria (Harrison et al., 2003; Kim et al., 2012; Rauha et al., 2000; Widmer and Laurent, 2006). The results show that leaves of tomato include more antimicrobial and antihervibore phenolic compounds than other parts.

\section{The Contents of Volatile Organic Compounds}

'Bacchus' tomato plants included 40 volatile organic compounds (Table 3). The contents of total volatile organic compounds were $444,206,152,111,108,82,37,30,26$, and $18 \mathrm{mg} \cdot \mathrm{m}^{-3}$ (fresh tissue) in red fruits, pink fruits, 24th leaves, 18th leaves, 21th leaves, green fruits, 18th internodes, 21th internodes, 24th internodes, and roots, respectively. The 2-butenal produced by the aldol condensation of acetaldehyde was the predominant volatile organic compound in red fruits; however, it was not detected in roots, leaves, internodes, and pink fruits. Leaves included six monoterpenes such as alpha-terpinene, alpha-phellandrene, beta-phellandrene, di-limonene, alpha-pinene, and sabinene. Buttery et al. (1987) reported that the leaves of the red cherry tomato contain eight monoterpenes (2-carene, myrcene, terpinolene, alpha-pinene, limonene, alpha-phellandrene, beta-phellandrene, and alpha-terpinene) and three sesquiterpenes ( $\delta$-elemene, caryophyllene, and humulene). The content of betaphellandrene in 18th leaves and sabinene in 24th leaves was higher than that in other parts. Tomato plants lay in volatile organic compounds in their glandular trichomes and the compounds are emitted by damage of the trichomes (van Schie et al., 2007). Herbivores increase the emission of the compounds from tomato trichomes because they have the ability to damage the trichomes (Gibson, 1971). In addition, sesquiterpene (alpha-humulene) was only detected in the 18th internodes. Degenhardt et al. (2003) reported that mono- and sesquiterpene are volatile compounds that attract herbivore enemies when plants were damaged by herbivores. The results show that the red fruits of tomato contained the highest contents of total volatile organic compounds, and the leaves of tomato contained the most diverse volatile organic compounds to attract herbivore enemies.

\section{The Contents of Alkaloids}

The content of dehydrotomatine was 889.11, 852.33, 817.05, 358.29, 269.72, 242.71, 59.11, 11.32, 7.89, and 7.51 $\mu \mathrm{g} \cdot \mathrm{g}^{-1} \mathrm{FW}$ in 24 th leaves, 21th leaves, 18th leaves, 24 th internodes, 21th internodes, 18th internodes, roots, green fruits, pink fruits, and red fruits, respectively (Table 4). The content of $\alpha$-tomatine was 1417.90, 1321.30, 1275.01, 307.36, 214.35, 167.52, 56.59, 43.02, 15.52, and $13.10 \mu \mathrm{g} \cdot \mathrm{g}^{-1}$ FW in 24th leaves, 21th leaves, 18th leaves, 24th internodes, 21th internodes, 18th internodes, roots, green fruits, pink fruits, and red fruits, respectively (Table 4). The contents of dehydro- and $\alpha$-tomatine were greatest in the leaves, followed by the internodes, roots and fruits. Younger leaves and internodes contained greater contents of dehydro- and $\alpha$-tomatine than older leaves and internodes. Friedman and Levin (1998) reported that leaves of tomato contained greatest dehydro- and $\alpha$-tomatine and the compounds in immature green fruits are partly degraded as the fruit development. Dehydro- and $\alpha$-tomatine in plants serve as natural defenses against fungi, bacteria, insects, and mammals. Especially, $\alpha$-tomatine that disrupts cell membrane by lysing of liposome has been implicated in plant defense (Morrissey and Osbourn, 1999). Boulogne et al. (2012) reviewed insecticidal and fungicidal activities of tomatine against Macrosiphum euphorbiae, Leptinotarsa decemlineata, Melanopus bivittatus, Heliothis zea, Hyposoterexiguae, Spodoptera exigua, Tribolium castaneum, Sitophilus oryzae, Fusarium solani, Nomuraea rileyi, and Fusarium oxysporum. The results showed that young leaves of tomato include more pesticidal alkaloids than other parts.

Pichersky and Gang (2000) reported that the ability to produce secondary metabolites has been selected throughout the process of evolution in different plant line ages when the compounds addressed specific needs. For instance, floral scent volatiles and pigments have evolved to attract pollinators and thus increase fertilization rates. The ability to synthesize toxic metabolites has evolved to ward off microorganisms and herbivores (from bacteria and fungi to insects and mammals) or to suppress the growth of other plants. The metabolites found in fruits prevent spoilage, and their color, aroma, and flavor signal the presence of potential rewards such as sugars, vitamins, and amino acids to animals who eat the fruit and thereby help seed dispersal. Other chemicals serve cellular functions that are unique to the particular plant in which they occur, such 
Table 3. The contents of volatile organic compounds in different parts of 'Bacchus' tomato plants.

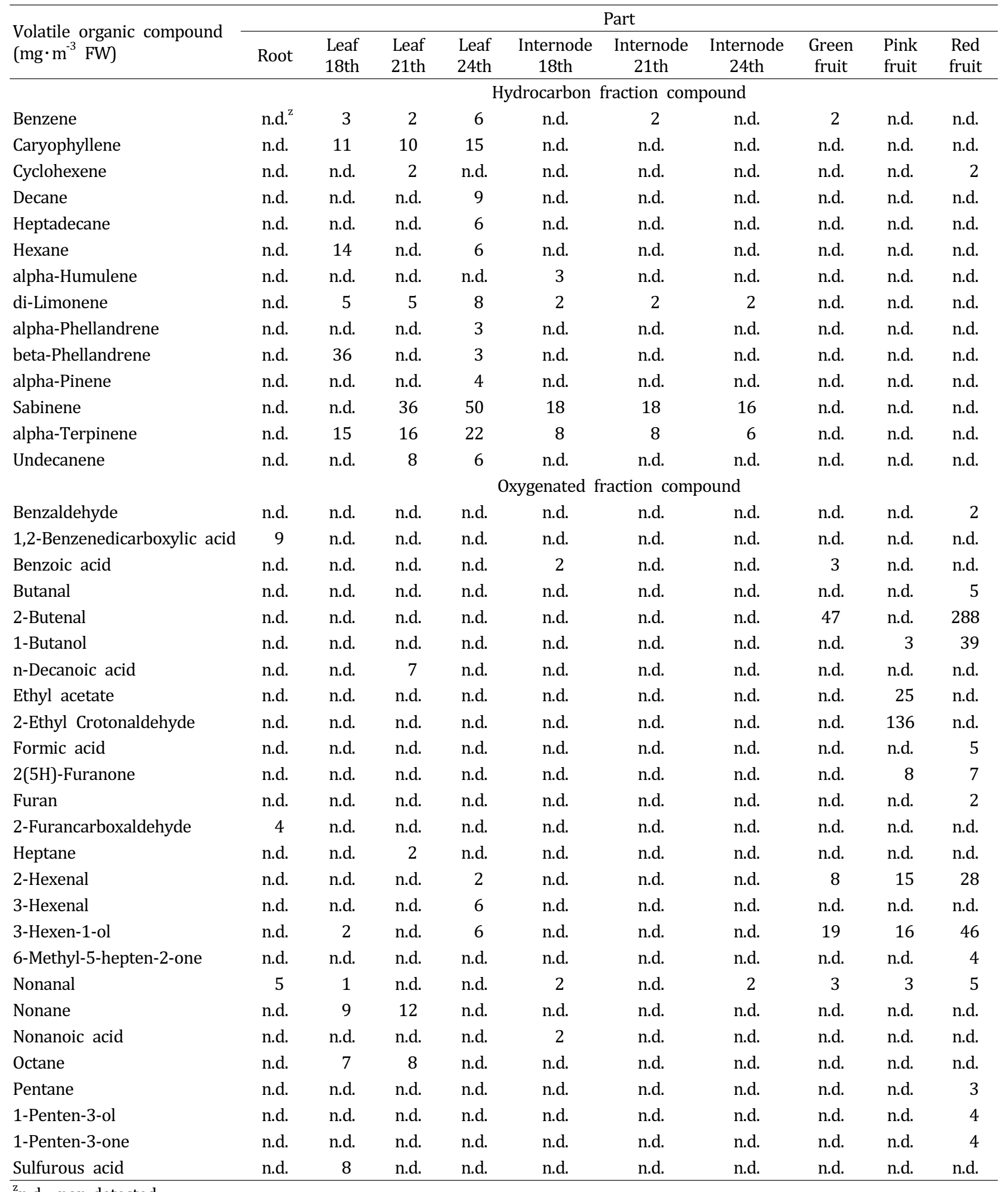

${ }^{\mathrm{z}}$.d.: non-detected. 
Table 4. The contents of tomatines in different parts of 'Bacchus' tomato plants.

\begin{tabular}{lcrr}
\hline \multirow{2}{*}{ Part } & & \multicolumn{2}{c}{ Alkaloids $\left(\mu \mathrm{g} \cdot \mathrm{g}^{-1} \mathrm{FW}\right)$} \\
\cline { 3 - 4 } & & Dehydro-tomatine & $\alpha$-tomatine \\
\hline Leaf & 18th & $817.05 \mathrm{c}^{\mathrm{z}}$ & $1,275.01 \mathrm{c}$ \\
& 21th & $852.33 \mathrm{~b}$ & $1,321.30 \mathrm{~b}$ \\
\multirow{2}{*}{ Internode } & 24th & $889.11 \mathrm{a}$ & $1,417.90 \mathrm{a}$ \\
& 18th & $242.71 \mathrm{e}$ & $1,67.52 \mathrm{~d}$ \\
& 21th & $269.72 \mathrm{e}$ & $214.35 \mathrm{~d}$ \\
Fruit & 24th & $358.29 \mathrm{~d}$ & $307.36 \mathrm{c}$ \\
& Green & $11.32 \mathrm{~g}$ & $43.02 \mathrm{e}$ \\
& Pink & $7.89 \mathrm{~g}$ & $15.52 \mathrm{e}$ \\
Root & Red & $7.51 \mathrm{~g}$ & $13.10 \mathrm{e}$ \\
& & $59.11 \mathrm{f}$ & $56.59 \mathrm{e}$ \\
\hline
\end{tabular}

${ }^{\mathrm{z}}$ Mean separation within columns by Duncan's multiple range test at $P<0.05$.

as resistance to salt or drought. We confirm that inedible parts (e.g., leaves, internodes, and unripe fruits) of tomato plants mainly included toxic compounds to microorganisms and insects (chlorogenic and caffeic acid, and tomatines) and edible parts contained pollinator attractants (lycopene and volatile compounds). Thus, after harvesting of fruits, the inedible parts of tomato plants can be used as a raw material for antioxidants, anti-inflammatory agents, fungistats, and pesticides.

\section{Literature Cited}

Aerts, R.J., T.N. Barry, and W.C. McNabb. 1999. Polyphenols and agriculture: Beneficial effects of proanthocyanidins in forages. Agr. Ecosyst. Environ. 75:1-12.

Akazawa, T. and K. Wada. 1961. Analytical study of ipomeamarone $\&$ chlorogenic acid alterations in sweet potato roots infected by Ceratocystis fimbriata. Plant Physiol. 36:139-144.

Andersson, B.A., R.T. Holman, L. Lundgren, and G. Stenhagen. 1980. Capillary gas chromatograms of leaf volatiles. A possible aid to breeders for pest and disease resistance. J. Agric. Food Chem. 28:985-989.

Astorg, P., S. Gradelet, R. Berges, and M. Suschetet. 1997. Dietary lycopene decreases the initiation of liver preneoplastic foci by diethylnitrosamine in the rat. Nutr. Cancer 29:60-68.

Bagchi, D., M. Bagchi, S.J. Stohs, D.K. Das, S.D. Ray, C.A. Kuszynski, S.S. Joshi, and H.G. Pruess. 2000. Free radicals and grape seed proanthocyanidin extract: Importance in human healthand disease prevention. Toxicology 148:187-197.

Boulogne, I., P. Petit, H. Ozier-Lafontaine, L. Desfontaines, and
G. Loranger-Merciris. 2012. Insecticidal and antifungal chemicals produced by plants: a review. Environ. Chem. Lett. 10:325-347.

Brown, P.D., J.G. Tokuhisa, M. Reichelt, and J. Gershenzon. 2003. Variation of glucosinolate accumulation among different organs and developmental stages of Arabidopsis thaliana. Phytochemistry 62:471-481.

Buttery, R.G., L.C. Ling, and D.M. Light. 1987. Tomato leaf volatile aroma components. J. Agric. Food Chem. 35:1039-1042.

Chen, H., A.D. Jones, and G.A. Howe. 2006. Constitutive activation of the jasmonate signaling pathway enhances the production of secondary metabolites in tomato. FEBS Lett. 580:2540-2546.

Clack, R.S., J. Kuc, R.E. Henze, and F.W. Quackenbush. 1959. The nature and fungitoxicity of an amino acid addition product of chlorogenic acid. Phytopathology 49:594-597.

D'Haeze, W. and M. Holsters. 2002. Nod factor structures, responses, and perception during initiation of nodule development. Glycobiology 12:79-105.

Deavours, B.E. and R.A. Dixon. 2005. Metabolic engineering of isoflavonoid biosynthesis in Alfalfa. Plant Physiol. 138:2245-2259.

Degenhardt, J., J. Gershenzon, I.T. Baldwin, and A. Kessler. 2003. Attracting friends to feast on foes: engineering terpene emission to make crop plants more attractive to herbivore enemies. Curr. Opin. Biotech. 14:169-176.

Di Mascio, P., M.E. Murphy, and H. Sies. 1991. Antioxidant defense systems: The role of carotenoids, tocopherols, and thiols. Amer. J. Clin. Nutr. 53:194-200.

Dixon, R.A. 2001. Natural products and plant disease resistance. Nature 411:843-847.

Elliger, C.A., Y. Wong, B.G. Chan, and A.C. Waiss, Jr. 1981. Growth inhibitors in tomato (Lycopersicon) to tomato fruitworm (Heliothis zea). J. Chem. Ecol. 7:753-758.

Farah, A. and C.M. Donangelo. 2006. Phenolic compounds in coffee. Braz. J. Plant Physiol. 18:23-36.

Fontaine, T.D., G.W. Irving, R. Ma, J.B. Poole, and S.P. Doolittle. 1948. Isolation and partial characterization of crystalline tomatine, an antibiotic agent from the tomato plant. Arch. Biochem. 18:467-475.

Fraser, P.D., M.R. Truesdale, C.R. Bird, W. Schuch, and P.M. Bramley. 1994. Carotenoid biosynthesis during tomato fruit development (evidence for tissue-specific gene expression). Plant Physiol. 105:405-413.

French, C.J. and G.H. Neil Towers. 1992. Inhibition of infectivity of potato virus X by flavonoids. Phytochemistry 31:3017-3020.

Friedman, M. and C.E. Levin. 1998. Dehydrotomatine content in tomatoes. J. Agric. Food Chem. 46:4571-4576.

Frydman, A., O. Weisshaus, M. Bar-Peled, D.V. Huhman, L.W. Sumner, F.R. Marin, E. Lewinsohn, R. Fluhr, J. Gressel, and Y. Eyal. 2004. Citrus fruit bitter flavors: Isolation and functional characterization of the gene Cm1,2 RhaT encoding a 1, 2 rhamnosyl transferase, a key enzyme in the biosynthesis of the bitter flavonoids of citrus. Plant J. 40:88-100.

Fuhrman, B., A. Elis, and M. Aviram. 1997. Hypocholesterolemic 
effect of lycopene and $\beta$-carotene is related to suppression of cholesterol synthesis and augmentation of LDL receptor activity in macrophages. Biochem. Bioph. Res. Commun. 233:658-662.

Gibson, R.W. 1971. Glandular hairs providing resistance to aphids in certain wild potato species. Ann. Appl. Biol. 68:113-119.

Gidley, M. 2004. Naturally functional foods - Challenges and opportunities. Asia Pac. J. Clin. Nutr. 13:S31.

Harrison, H.F., J.K. Peterson, M.E. Snook, J.R. Bohac, and D.M. Jackson. 2003. Quantity and potential biological activity of caffeic acid in sweet potato (Ipomoea batatas (L.) Lam.) storage root periderm. J. Agric. Food Chem. 51:2943-2948.

Isleten, M. and Y. Karagül-Yüceer. 2008. Effects of functional dairy based proteins on nonfat yogurt quality. J. Food Quality 31:265-280.

Jiménez-Escrig, A., I. Jiménez-Jiménez, C. Sánchez-Moreno, and F. Saura-Calixto. 2000. Evaluation of free radical scavenging of dietary carotenoids by the stable radical 2,2-diphenyl-1picryl-hydrazyl. J. Sci. Food Agric. 80:1686-1690.

Johnson, G. and L.A. Schaal. 1957. Chlorogenic acid and other orthodihydricphenolsin scab-resistant Russet Burbank and scabsusceptible Triumph potato tubers of different maturities. Phytopathology 47:253-255.

Kähkönen, M.P., A.I. Hopia, H.J. Vuorela, J.P. Rauha, K. Pihlaja, T.S. Kujala, and M. Heinonen. 1999. Antioxidant activity of plant extracts containing phenolic compounds. J. Agric. Food Chem. 47:3954-3962.

Kim, D.S., H. Na, J.H. Song, Y. Kwack, S.K. Kim, and C. Chun. 2012. Antimicrobial activity of thinned strawberry fruits at different maturation stages. Kor. J. Hort. Sci. Technol. 30:769-775.

Kim, D.S., H. Na, Y. Kwack, S.K. Kim, J.W. Heo, and C. Chun. 2013. Composition of secondary metabolites in various parts of 'Seolhyang' strawberry plants. Kor. J. Hort. Sci. Technol. 31:224-230.

Kozukue, N. and M. Friedman. 2003. Tomatine, chlorophyll, $\beta-$ carotene and lycopene content in tomatoes during growth and maturation. J. Sci. Food Agric. 83:195-200.

Lenucci, M.S., D. Cadinu, M. Taurino, G. Piro, and G. Dalessandro. 2006. Antioxidant composition in cherry and high-pigment tomato cultivars. J. Agric. Food Chem. 54:2606-2613.

Manach, C., A. Scalbert, C. Morand, C. Rémésy, and L. Jiménez. 2004. Polyphenols: Food sources and bioavailability. Amer. J. Clin. Nutr. 79:727-747.

Merz-Demlow, B.E., A.M. Duncan, K.E. Wangen, X. Xu, T.P. Carr, W.R. Phipps, and M.S. Kurzer. 2000. Soy isoflavones improve plasma lipids in normocholesterolemic, premenopausal women. Amer. J Clin. Nutr. 71:1462-1469.

Moco, S., E. Capanoglu, Y. Tikunov, R.J. Bino, D. Boyacioglu, R.D. Hall, J. Vernoort, and R.C.H. De vos. 2007. Tissue specialization at the metabolite level is perceivedduring the development of tomato fruit. J. Exp. Bot. 58:4131-4146.

Morrissey, J.P. and A.E. Osbourn. 1999. Fungal resistance to plant antibiotics as a mechanism of pathogenesis. Microbiol. Mol.
Biol. Rev. 63:708-724

Nuutila, A.M., K. Kammiovirta, and K.M. Oksman-Caldentey. 2002. Comparison of methods for the hydrolysis of flavonoidsand phenolic acids from onion and spinach for HPLC analysis. Food Chem. 76:519-525.

Oldroyd, G.E.D. 2001. Dissecting symbiosis: Developments in Nod factor signal transduction. Ann. Bot. 87:709-718.

Pichersky, E. and D.R. Gang. 2000. Genetics and biochemistry of secondary metabolites in plants: An evolutionary perspective. Trends Plant Sci. 5:439-445.

Rao, A.V. and S. Agarwal. 1999. Role of lycopene as antioxidant carotenoid in the prevention of chronic diseases: A review. Nutr. Res. 19:305-323.

Rauha, J.P., S. Remes, M. Heinonen, A. Hopia, M. Kähkönen, T. Kujala, K. Pihlaja, H. Vuorela, and P. Vuorela. 2000. Antimicrobial effects of Finnish plant extracts containing flavonoids and other phenolic compounds. Intl. J. Food Microbial. 56:3-12.

Relić, B., X. Perret, M. Estrada-García, J. Kopcinska, W. Golinowski, H.B. Krishnan, S.G. Pueppke, and W.J. Broughton. 1994. Nod factors of Rhizobium are a key to the legume door. Mol. Microbiol. 13:171-178.

Rohloff, J. and A.M. Bones. 2005. Volatile profiling of Arabidopsis thaliana - putative olfactory compounds in plant communication. Phytochemistry 66:1941-1955.

Ronen, G., M. Cohen, D. Zamir, and J. Hirschberg. 1999. Regulation of carotenoid biosynthesis during tomato fruit development: Expression of the gene for lycopene epsilon-cyclase is downregulated during ripening and is elevated in the mutant Delta. Plant J. 17:341-351.

Sadler, G., J. Davis, and D. Dezman. 1990. Rapid extraction of lycopene and $\beta$-carotene from reconstituted tomato paste and pink grapefruit homogenates. J. Food Sci. 55:1460-1461.

Sandrock, R.W. and H.D. Van Etten. 1998. Fungal sensitivity to andenzymatic degradation of the phytoanticipin $\alpha$-tomatine. Phytopathology 88:137-143.

van Schie, C.C.N., M.A. van Haring, and R.C. Schuurink. 2007. Tomato linalool synthase is induced in trichomes by jasmonic acid. Plant Mol. Biol. 64:251-263.

Setchell, K.D.R. and A. Cassidy. 1999. Dietary isoflavones: Biological effects and relevance to human health. J. Nutr. 129:758-767.

Slimestad, R. and M. Verheul. 2009. Review of flavonoids and other phenolics from fruits of different tomato (Lycopersicon esculentum Mill.) cultivars. J. Sci. Food Agric. 89:1255-1270.

Stamp, N.E. and Y. Yang. 1996. Response of insect herbivores to multiple allelochemicals under different thermal regimes. Ecology 77:1088-1102.

Todd, G.W., A. Getahun, and D.E. Cress. 1971. Resistance in barley to the greenbug, Schizaphis graminum. 1. Toxicity of phenolic and related compounds and related substances. Ann. Entomol. Soc. Amer. 64:718-722.

Urbasch, I. 1981. Antimycotic activity, volatile metabolites from the leaves of tomato plants. Naturwissenschaften 68:204-205. 
Uritani, I. and T. Akazawa. 1955. Antibiotic effect on Ceratostomella fimbriata of ipomeamarone, an abnormal metabolite in black rot of sweetpotato. Science 121:216-217.

Verdonk, J.C., C.H. Ric de Vos, H.A. Verhoeven, M.A. Haring, A.J. van Tunen, and R.C. Schuurink. 2003. Regulation of floral scent production in petunia revealed by targeted metabolomics. Phytochemistry 62:997-1008.

Verpoorte, R. and J. Memelink. 2002. Engineering secondary metabolite production in plants. Curr. Opin. Biotech. 13:181-187.

Walker, J.R.L. 1962. Phenolic acids in 'cloud' and normal tomato fruit wall tissue. J. Sci. Food Agric. 13:363-367.
Wardale, D.A. 1973. Effect of phenolic compounds in Lycopersicon esculentum on the synthesis of ethylene. Phytochemistry 12: 1523-1530.

Widmer, T.L. and N. Laurent. 2006. Plant extracts containing caffeic acid and rosmarinic acid inhibit zoospore germination of Phytophthora spp. pathogenic to Theobroma cacao. Eur. J. Plant Pathol.115:377-388.

Zhang, L.X., R.V. Cooney, and J.S. Bertram. 1991. Carotenoids enhance gap junctional communication and inhibitlipid peroxidation in C3H/10T1/2 cells: Relationship to their cancer chemopreventive action. Carcinogenesis 12:2109-2114. 